\title{
DEVELOPMENT OF COMPETENCIES IN A TRANSDISCIPLINARY ENVIRONMENT THROUGH CHALLENGE-BASED LEARNING
}

\author{
Luis Miguel GUTIÉRREZ, Rebeca TORRES, Stefania BIONDI, Claudio SARMIENTO and \\ Alejandro ACUÑA \\ Tecnologico de Monterrey
}

\begin{abstract}
Over a course of 5 weeks, undergraduate students of the "Creative Studies" entry, developed a research based on discovering insights focusing on cultural and social aspects on a previously selected community into the city of Querétaro, México. The students are enrolled in a new educational model in which they study their first year with an exploration academic core and then they select their major field in order to eventually graduate with a minor specialization.

In the 5 week course, the students developed a secondary investigation to contextualize themselves before beginning the collection of data on site. Work in the field and in the classroom was alternated to guarantee experiential and immersive learning based on theoretical content taught in the classroom and then applied on field.

This paper describes the process to discover the main findings in the implementation of this new academic structure called Block, in which there are content modules, a research challenge and the evaluation of research and transversal competencies.
\end{abstract}

Keywords: Competencies-based learning, challenge-based learning, transdisciplinary ambient, educational innovation

\section{INTRODUCTION}

Tecnologico de Monterrey is a private multi-campus university with headquarters in Monterrey, Nuevo León, Mexico. Since 2015, a new educational model has been implemented at the Tecnologico de Monterrey, called Tec21 Model. This new educational model into the institution is designed in a particular way in the youth of the new century. As of August 2019, a new academic structure called Block was implemented: a multidisciplinary project consisting of learning modules and the resolution of a challenge. This paper will describe the methodology and implementation into the Block structure on the course "Research Methods and Human Factors". This Block was carried out in two of the most traditional neighbourhoods of the city of Querétaro and with the participation of freshmen from the entrance of Creative Studies, the disciplines of Industrial Design, Architecture, Digital Art, among others. This paper is a descriptive approach to the design and implementation process of the course through the exercises and activities developed by the students.

\section{METHODOLOGY}

For the realization of the Blocks, as it happened at the time with "Semester i" [1], it was required to break with educational paradigms at the professional level. Each of the aspects of the Block methodology are described below.

The Block is divided in three complimentary modules in which each student will learn the theoretical knowledge that will help them to accomplish the Challenge activities, in order to build their evidence that will be the tool to grade the competencies declared in the course.

At the August-December 2019 semester 4 groups were programmed in the campus, each one with different mixtures depending on type of students, number of teachers, type of activities and the community visited to do the field research. 
The interdisciplinary environment was given by the diversity in the teacher's background and student's profile. The teachers were selected by their disciplinary approach to the topics of the course and the students were mixed randomly by their registration with no particular election criteria.

The diversity of these variables allowed each group to work with different styles, mainly determined by the community to visit but the teachers were the principal factor to guide the way in which the activities were to be implemented directly on the field. It happened due to the teacher's profile and their experience with the research methods that they apply in their profession. A general description of the Block can be seen in figure 1.

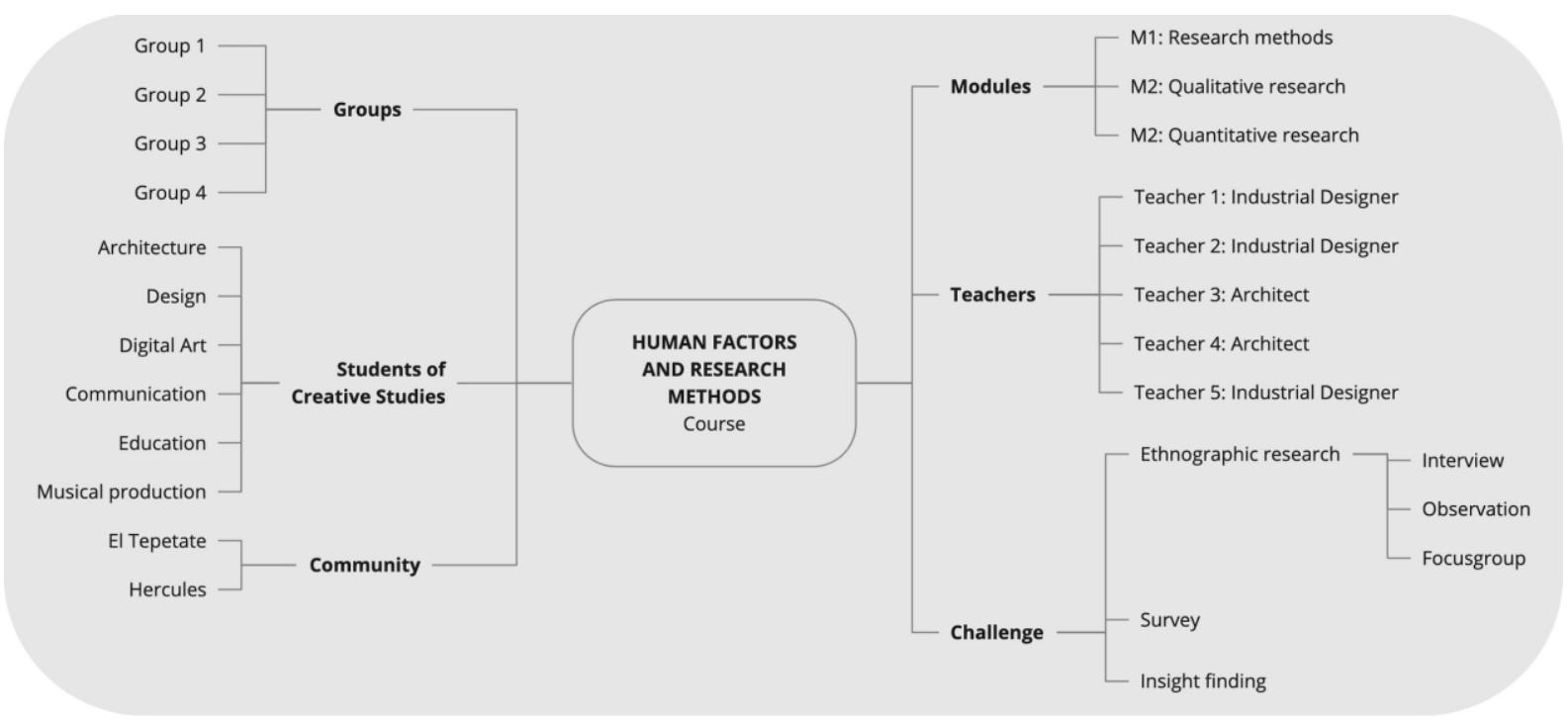

Figure 1. Course structure

\subsection{Context}

"Creative Studies" is one of the lines from the undergraduate introductory programmes that the institution offers to their new students.

The entry into Creative Studies has a duration of two semesters and the main objective is to learn to handle various languages and technologies related to the conceptualization and creative creation, to design and produce projects and multidisciplinary solutions for various professional fields: architectural, digital art, design, communication and journalism, education, literature, and musical production [2].

Along this year the students explore all the creative possibilities of creative knowledge and give them the tools to generate creative thinking approaching holistic solutions to wicked problems from a lateral perspective. After these two semesters, the students have to decide in which major programme they will decide to study.

The Tec21 model has the "Challenge" as the centre of the learning process. Something important to consider is the problematization of a current situation for defining a complex challenge, which needs to be relevant not only for students but also for society, providing a unique opportunity to explore the role that universities must have in the value creation beyond academic purposes. To this extent, a design brief was defined in order to provide a shared perspective upon the research approach during the course. The Block of Research Methods and Human Factors is structured to contribute with the critical thinking of the students developing curiosity for knowledge and empathy to the others.

\subsection{Course}

The new educational model demands the "Challenge" as the centre of all the efforts from students and teachers. In the Block of Research Methods and Human Factors the aim is to focus on the activities and all the topics in the approach to work in teams that collect information and relevant data to find insights by researching in the community.

The Challenge represents an opportunity to learn something new and strengthen what the student already knows by solving a given problem. Is mandatory to bond with educational partners that are not specifically educational institutions but companies, organizations and/or communities that allow the students to learn in different environments, not only at school. 
The challenge was named as: Recognizing the elements that define the identity of the traditional neighbourhoods of the city of Querétaro and the aim of this exercise was to allow the students to understand the elements that define the neighbourhood identity not only as an activity that contributes to the remanence of cultural diversity in the communities but as a protection strategy for the neighbours themselves against interests that are seldom aligned with political needs, a strategy that makes visible what is valued in the communities and that largely defines the quality of life of the neighbours. The trigger question given to the students was: How could we generate new parameters that allow us to communicate the neighbourhood identity?

The main objective of this challenge is to develop in the students their capacities to develop specific competencies thus, applying procedures for the study of local groups and communities, demonstrating commitment to the priorities for community development.

The competencies developed were:

- Identify needs, desires and behavioural patterns, preferences, and public's consumption, applying qualitative and quantitative methods.

- $\quad$ Solve problems and questions of reality, based on valid and reliable methodologies.

The three modules are taught one per week by different teachers, but the Challenge runs in a transversal way covering all the activities performed by the students in order to collect all the evidence that confirms that the competencies were acquired along the five weeks. A teacher is required to supervise the Challenge and guide the students to cover all the aspects of the Brief in order to assemble their evidence to achieve the competencies as seen on Figure 2.

\section{Course Challenge}

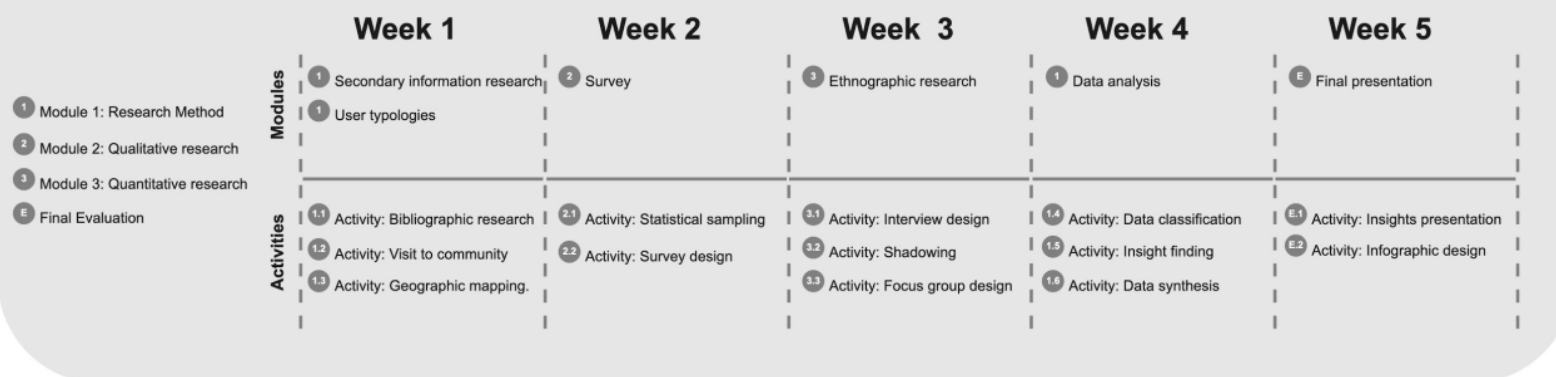

Figure 2. Challenge structure

In the Block of Research Methods and Human Factors the core theme consisted in approaching insight finding the identity of the community beyond what the state identifies as cultural and social value. Gentrification and touristification were two topics discussed among students, as well as how the cultural heritage of the community are assets constantly threatened by the tourism market. The research opportunity emerged by understanding the diverse elements that are part of a community identity, which defines as well, the quality of life for its residents.

Therefore, the challenge for students consisted in identifying and recognizing the daily practices that are part of the identity of the community, looking to generate new parameters enabling to communicate what is valued in the territory by people of these places, beyond infrastructure, investment, or access to services.

As part of the methodology, students were asked to visit and explore the territory. During the first visit, students were constantly encouraged to think and question how identity is represented in the different elements of the community: from the local traditions, economic and social activities, as well as cultural expressions.

The Block is divided by Modules that structure the theoretical knowledge and allows the student to scaffold their approach into the Challenge. The Research Methods and Human Factors will be described as follows. 


\subsection{Module Distribution \\ 2.3.1 M1 Research Method}

The main focus of this module is to introduce the students into the importance of applying research methods in the creative activities in which they eventually are enrolled.

The first part is aimed to provide theoretical knowledge about the research methods, the students start the course with a lecture of history that frames the context of the discipline and enforces the cognitive abilities into the classroom and provides a strong concept of a research project applied into a real context. The second part is focused on the analysis and synthesis of the information gathered during the Qualitative and Quantitative research methods into the approach to discover powerful insights that determine the identity traits of the specific community that had been studied by the group of students.

As evidence, each team delivers an executive document in which they attach all the information obtained during the primary and secondary research complimented by the discovery of results and findings and the future recommendations. At the end of the module every team presents the information to the teachers and the community and delivers infographic material to spread the insights to the rest of the inhabitants.

\subsubsection{M2 Qualitative research}

The qualitative module aimed to go into detail to the students' research question and through different research methods such as interviews and observations, provide answers to it [3]. The aim is to bring students to know and design some tools that they could apply in the field to inquire about the sense of identity and belonging perceived by the community. It was important, therefore, that the abstract knowledge be complemented with exercises that facilitate the understanding and use of the instruments (mainly observation guides and guides to direct focus groups and interviews) that would be applied in the field.

For this reason, the teaching of the module has been based on two moments: one of explanation of the techniques by the teacher, another of design of the guides and put into practice in an experimental way, in the classroom, under the supervision of the teacher.

Besides the interviews, students needed to develop a guide for observation in the territory. Based on the Gehl method, each team needed to select two tools which they considered necessary to capture the elements of the local barrio and for providing answers to their research question.

\subsubsection{M3 Quantitative research}

The quantitative module aimed to introduce the students to the research methodology as well as to the territory as a place to develop research. The use of quantitative research methods in the development of design projects might not be entirely clear for students in the social sciences, the humanities, or other creative disciplines. In fact, it is fairly common that students choose these professions precisely because they are not confident in their knowledge or ability to use quantitative methods [4]. The Quantitative Methods module was therefore planned with these preconceptions in mind - fully expecting students to be sceptical about how design can be analysed through quantitative methodologies, or possibly anxious about the use of statistics in research.

Given the short time frame of the course, the goal of this module focus was that the students developed solid criteria for identifying, choosing, and further investigating the quantitative methods best suited to answer a given research question. Indeed, scholars teaching in the social sciences have come to the conclusion that it is more effective for students to be able to understand key ideas presented in quantitative research, than to master the use of statistics software packages [5].

Based on the first visit students were asked to develop their research question, aiming to frame their own research interests after the first field study visit. They also established the population group that needed to approach in order to respond to their research question.

After this first deliverable, students were asked to develop a questionnaire with a minimum of six questions and a maximum of ten. This tool extremely helped students to understand much better how in practice researchers define the concepts, variables, and indicators. Also, it was crucial for students to start with the research as well as to find topics to be further research during the qualitative module.

\subsection{Competencies}

The sub competencies to be developed in this Block, at a basic level of mastery, are the following: Identify needs, desires and behaviour patterns and preferences of users, applying qualitative and 
quantitative methods (disciplinary sub competency).

Scientific thinking: Solve problems and questions of reality based on objective, valid methodologies and reliable (transversal sub competency).

\subsection{Evaluation}

The students were evaluated by the delivery of an evidence which was formulated as a Research Report where the students framed within the acquaintance of knowledge related with Human Factors Research, whose main objective is to develop their abilities to identify needs, behaviour patterns and preferences of the public in their immediate environment, applying basic methods qualitative and quantitative; through knowledge and application of basic techniques and procedures of qualitative and quantitative research; thus applying procedures for the study of local groups and communities, demonstrating commitment to community development priorities. Such evaluation is based on the observation of the competencies developed during the course and the numerical grading of the quality of the research report.

Besides the Research Report, the students developed infographic material and introduced the results as a keynote in a conference to all the interested in accomplishment to present the relevant insights and findings to the audience.

\section{RESULTS AND FINDINGS}

The modules within the course look to emphasize the importance of developing a new attitude towards people through the acknowledgement that their experiences and stories are the best assets for any creative process. The activities designed for the course, developed students' capacities in finding and setting opportunities for creative intervention through research, rather than simply seeking solutions to needs expressed [6].

This became evident in the students' projects. Below we present images of the presentation to the community and two examples of deliverables.
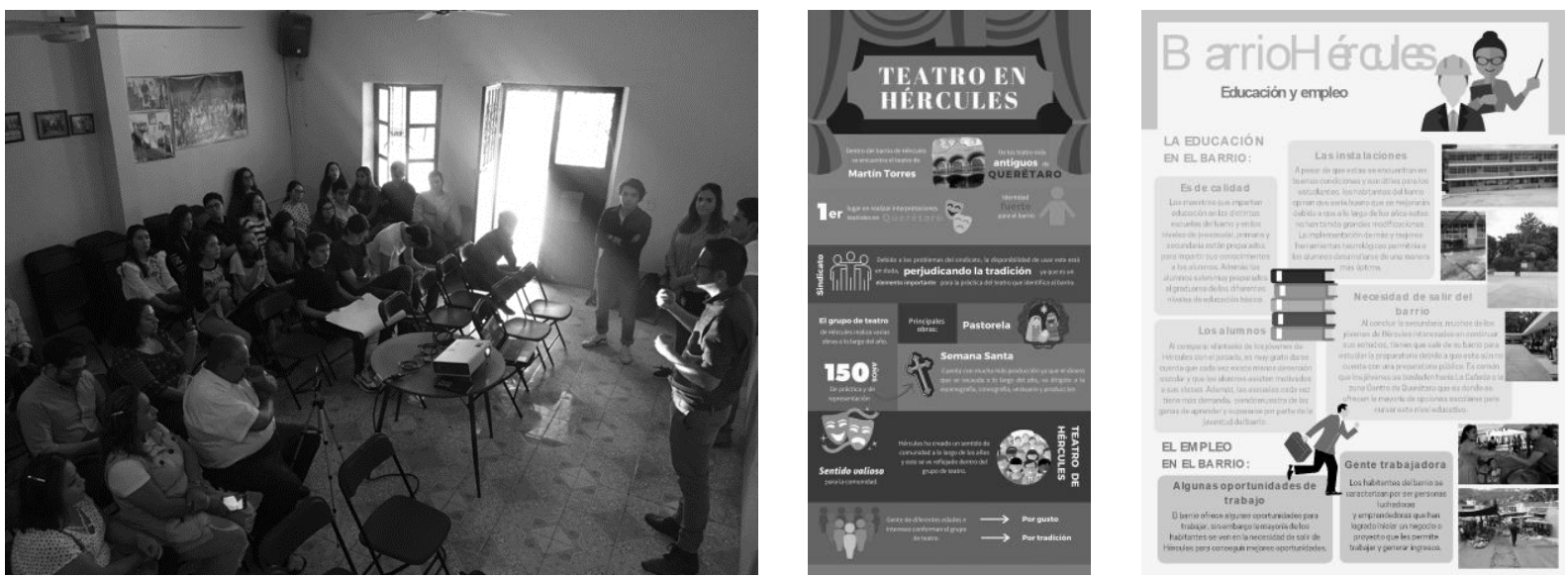

Figures 3-5. Presentation to the community and examples of deliverables

The research methods employed by the student should be chosen according to the research question, and not based on the student's chosen profession, ideological preference, or preconceived ideas about their difficulty [7]. Likewise, instructors of this module should have ample experience not only in utilizing both quantitative and qualitative methods, but in knowing how to mix them for the purpose of strengthening the quality of social research.

\subsection{Students opinions}

The comments of the students have revealed three successful aspects of the course; while they have judged negatively only the temporal factor: "Time too short to complete the work fully". It is possible that students tend to express their satisfaction and complacency in a somewhat conformist and uncritical way, since they think they should please the teacher.

However, it can be rescued with some authentic testimonies about the importance of undertaking research prior to the realization of a project: "I had the opportunity to know people that live in different situations than me, I could empathize with them". 
These have focused on the appreciation of the experience of immersion in the field, the listening and recognition of the other as a bearer of knowledge. Some students have clearly noticed the pleasure and surprise at the discovery; and this has gone hand by hand with self-appreciation, the awareness of acquiring new skills.

\section{CONCLUSIONS}

The physical approach to the object of study favours empathy with the same and with the other subjects involved in the process. It was useful and proficient to be able to apply the revised procedures in the classroom in concrete realities and close to the students, so that they could feel a greater commitment to the research topic.

But the difficulties in planning and executing a successful module on quantitative and qualitative methods were compounded with the time constraints baked into this course. As noticed before, the goal of the modules was to familiarize students with this family of methods while giving them a chance to explore them on their own through a practical challenge. However, instructors should be careful of mistaking expedited learning with poorly executed quantitative research. While students gain valuable experience in formulating and conducting structured questionnaires, for example, they should also be made aware of the constraints of sample size and statistical significance when presenting their conclusions.

The mixture of students and teacher profiles and the community selected for the group gave an interesting variation on the format of the final deliverables and the focus in which the research method was taught. In one community the people were very participative with the group but in the other it was an organization linked with the inhabitants and their everyday activities because it was harder to obtain the information, the people were reluctant to share with the students. It gave teachers the opportunity to approach from a different perspective to the phenomena. The students' vision was determined by the ethnographic tools used in the research, changed the way in which they prepared their final conclusions. Although those fluctuations variate the final perspective on the approach to the Challenge and the way in that the students developed empathy and respect for the diversity was homogeneous in the core due to the sensibilization on critical topics like the decolonization, gentrification, and human factors in general.

\section{ACKNOWLEDGMENTS}

The authors would like to acknowledge the financial support of Writing Lab, Institute for the Future of Education, Tecnologico de Monterrey, Mexico, in the production of this work. It is appreciated all the collaboration given by the strategic contacts and partners inside the communities "El Tepe" and "Hércules".

\section{REFERENCES}

[1] Acuña A., Maya M., Britton E., and García M. Play lab: creating social value through competency and challenge-based learning. In DS 88: Proceedings of the 19th International Conference on Engineering and Product Design Education (E\&PDE17), Building Community: Design Education for a Sustainable Future, Oslo, Norway, 7 \& 8 September 2017 (pp. 710-715).

[2] Estudios Creativos, Tecnológico de Monterrey. Available: https://tec.mx/es/estudios-creativos [Accessed on 2020, 12 January]

[3] Maxwell J. A. Designing a qualitative study. The SAGE handbook of applied social research methods, 2008, 2, 214-253.

[4] Cienfuegos M. A. and Cienfuegos A. Lo cuantitativo y cualitativo en la investigación. Un apoyo a su enseñanza. Revista Iberoamericana para la Investigación y el Desarrollo Educativo, 2016, 7(13), 15-36.

[5] Vasco Uribe C. E. El debate recurrente sobre la investigación cuantitativa y la cualitativa. Nómadas (Col), 2003, (18), 28-34.

[6] Mathisen G. E. and Bronnick K. S. Creative self-efficacy: An intervention study. International Journal of Educational Research, 2009, 48(1), 21-29.

[7] Campos R. M. (2007). El (falso) problema cuantitativo-cualitativo. Liberabit, 2007, (13), 5-18. 